\title{
The potential distribution and risk assessment of Pratylenchus zeae on maize in Belgium and the Netherlands
}

\begin{abstract}
A pest risk assessment (PRA) was carried out on Pratylenchus zeae on maize as host in Belgium and the Netherlands as the pest risk assessment areas where the organism is yet to be reported owing to potential phytosanitary concerns that its introduction to this areas might cause economically. To assess the potential geographic distribution of the pest in the study areas and other areas in Europe out of its current areas of occurrence, two tools were used for the study; CLIMEX, a computer simulation model and the European and Mediterranean Plant Protection Organization PRA guidelines to see if the pests can be introduced and established in the pest risk assessment areas. Geographic distribution data for P. zeaein its current locations were used to fit parameter values in the CLIMEX program. The CLIMEX analysis suggests that P. zeaecan potentially become introduced in one of the study area and other parts of Europe and other climatically suitable regions of the world. The conclusion from the study was based on the combination of the results from both CLIMEX and the PRA guidelines since the use of only one may not give very reliable results. CLIMEX works mainly with climatological data while the PRA guidelines involve the use of biological data for which most are not available for the organisms. The analysis of Pratylenchus zeae which in Europe was only reported in Bulgaria and most recently in Slovenia, Austria, Croatia and Turkey, shows that the pest can become established upon introduction through plant and plant materials moving in trade in Belgium and not in the Netherlands although its effect on crop yield maybe low due to cooler climates obtainable in this areas. Because of its very low impact after introduction, the pest does not have the characteristics of a quarantine organism.
\end{abstract}

Keywords: pratylenchus zeae, CLIMEX, pest risk assessment, maize, simulation model, parameter fitting; degree-days
Volume 2 Issue 5 - 2015

\author{
Ndonkeu TWalter,' Gerrit Karssen² \\ 'Entomology Unit, Earth University, Costa Rica \\ 2Department of Nematology, Wageningen University and \\ Research Centre, Netherlands
}

Correspondence: Ndonkeu T Walter, Entomology Unit, Earth University, San Jose, Costa Rica, PO Box 4442-1000,Tel +50627130102, Email nwalter@earth.ac.cr

Received:June 15, 2015 | Published: August 27, 2015
Abbreviations: PRA, pest risk analysis; EPPO, european and mediterranean plant protection organization; PDD, degree-days per generation; EI, ecoclimatic index

\section{Introduction}

Pratylenchus zeae commonly known as the root lesion nematode is a key nematode pest of a number of tropical and sub-tropical graminaceous crops. ${ }^{2}$ The pest infectsa great variety of host which include but not limited to; sugarcane, ${ }^{3}$ plantain, ${ }^{4}$ maize, $, 5,6$ rice, ${ }^{7}$ soybeans ${ }^{8}$ and papaya. ${ }^{9}$ In spite of its wide host range, it has few specific habitat requirements and does not survive in permanently flooded conditions. ${ }^{10}$ On maize, Pratylenchus zeae a migratory endoparasite, causes a mechanical breakdown on root cells and necrosis of stellar and cortical tissues resulting in formation of cavities. ${ }^{11}$

Necrotic lesions can be observed on the root surface. Damage is non-specific: the nematodes reduce top and root growth, which is seen as stunted and chlorotic plants in patches in the field. Pratylenchus zeae is a migratory endoparasite of the root cortex, entering smaller roots at any point. All stages are found in the outer parenchyma cells and never in the vascular tissues. Eggs are laid either single or in small groups of 3-4, in roots and in the soil. Hatching takes 15-20days. ${ }^{1}$ Reproduction of Pratylenchus zeae is greatest at $30^{\circ} \mathrm{C}$. One generation takes approximately 21 days on maize. ${ }^{11}$
The population of nematode may increase significantly under continuous maize cropping eventually resulting in considerable yield losses. ${ }^{2,12,13}$ Indirect evidence has been obtained with nematicides where the detected yield increase suggested that root lesion nematodes in general are important limiting factors in maize cultivation. Yield increases in maize were however recorded following the application of nematicides. ${ }^{14-16}$

Despite the fact that this pest has a worldwide distribution, it was first reported in Europe only in Bulgaria ${ }^{17}$ and most recently one record has been reported in the following countries; Austria, Slovenia and Croatia ${ }^{18}$ and Turkey. ${ }^{19}$

The aim of the present study was to conduct a pest risk assessment (PRA) of Pratylenchus zeae on maize in Belgium and the Netherlands after it has been recorded in other localities as primary pest of maize causing great yield reduction. The analysis follows the Pest Risk Assessment guideline of $\mathrm{EPPO}^{20}$ and the use of CLIMEX, which is a dynamic simulation model for predicting the effects of climate on the distribution of plants and animals, by using climatic parameters inferred from an observed distribution. It is applied to different biological entities by selecting the values for the parameters that describes the organism's response to temperature, moisture and light. CLIMEX uses climate information, and knowledge about the biology and distribution of species in their original habitat, to provide 
a rapid, reliable assessment of the risks posed by the introduction of various organisms, and can be used to predict their potential area of distribution. The climatic requirements of a species are inferred from its known geographical distribution (either in its native range or in another region where it has been established for a long time), relative abundance and seasonal phenology.

The CLIMEX simulation model is a popular software program ${ }^{21,22}$ for carrying out risk assessments for arthropod pests, weeds, and diseases. ${ }^{23-30}$ CLIMEX has the advantages, in comparison to other climate modeling softwares, that it includes a global meteorological database, which enables its Compare Locations module to be processoriented. This therefore suggests that it is relatively resistant from the new climates problem that climate-matching and descriptive statistical models mighty encounter thus limiting their ability to perform global risk assessments.

Even though P. zeae is not widely distributed in Europe, it has the potential to extend its current range into new countries in the continent, through transportation of infected seed and grain. This paper reports an analysis undertaken to estimate the potential distribution and establishment of $P$. zeae based on ecoclimatic suitability and the pest risk analysis guidelines so as to be able to predict occurrence of the study organisms in the study areas. The CLIMEX test was carried out at the Plant Protection service in Wageningen in the Netherlands were the program is available.

\section{Materials and methods}

The computer simulation model CLIMEX version $2.0,{ }^{22}$ was used to determine the potential world geographic distribution of $P$. zeaein general (Figuer 1A) and in continental Europe in particular in relation to its presently known geographic distribution (Figure 1B). The CLIMEX software program uses a database of meteorological climate station data which are normally recorded as monthly means, and then interpolates this data to weekly values. The meteorological database supplied with the CLIMEX model is based on the database from the World Meteorological Organization.

Parameter fitting: The main parameter groups used are: temperature index, moisture index, cold stress, heat stress, dry stress and wet stress (Table 1). Parameters that are not readily available are obtained from the parameter template, representative of different geographical distributions that are provided with the CLIMEX program. ${ }^{22}$

Temperature parameters: The temperature parameters were initially based on the reported findings of. ${ }^{10,32}$ DV0 (lower temperature threshold for growth) was set to $10^{\circ} \mathrm{C}$, because it is at this low level of temperature that germination, infection, and lesion production occur. DV1 (lower optimum temperature for growth), DV2 (upper optimum temperature for growth), and DV3 (upper temperature threshold for growth) set at 15,30 and $35^{\circ} \mathrm{C}$, respectively, were based on temperature reports of. ${ }^{10,32}$

Moisture parameters: The moisture parameters were set to maximize the growth potential of $P$. zeae in Bulgaria where it was first reported in Europe. The permanent wilting point of plants is generally near $10 \%$ soil moisture, and so the lower soil moisture threshold (SM0) of 0.1 reflects the need of $P$. zeae for more than the minimal amount of moisture to sustain its hosts' growth. The upper soil moisture threshold allows $P$. zeaeto grow during run-off conditions and the lower and upper optimum thresholds (SM1and SM2) define a relatively broad but wet range of soil moisture conditions that should be optimal for the growth of Pratylenchus zeae.

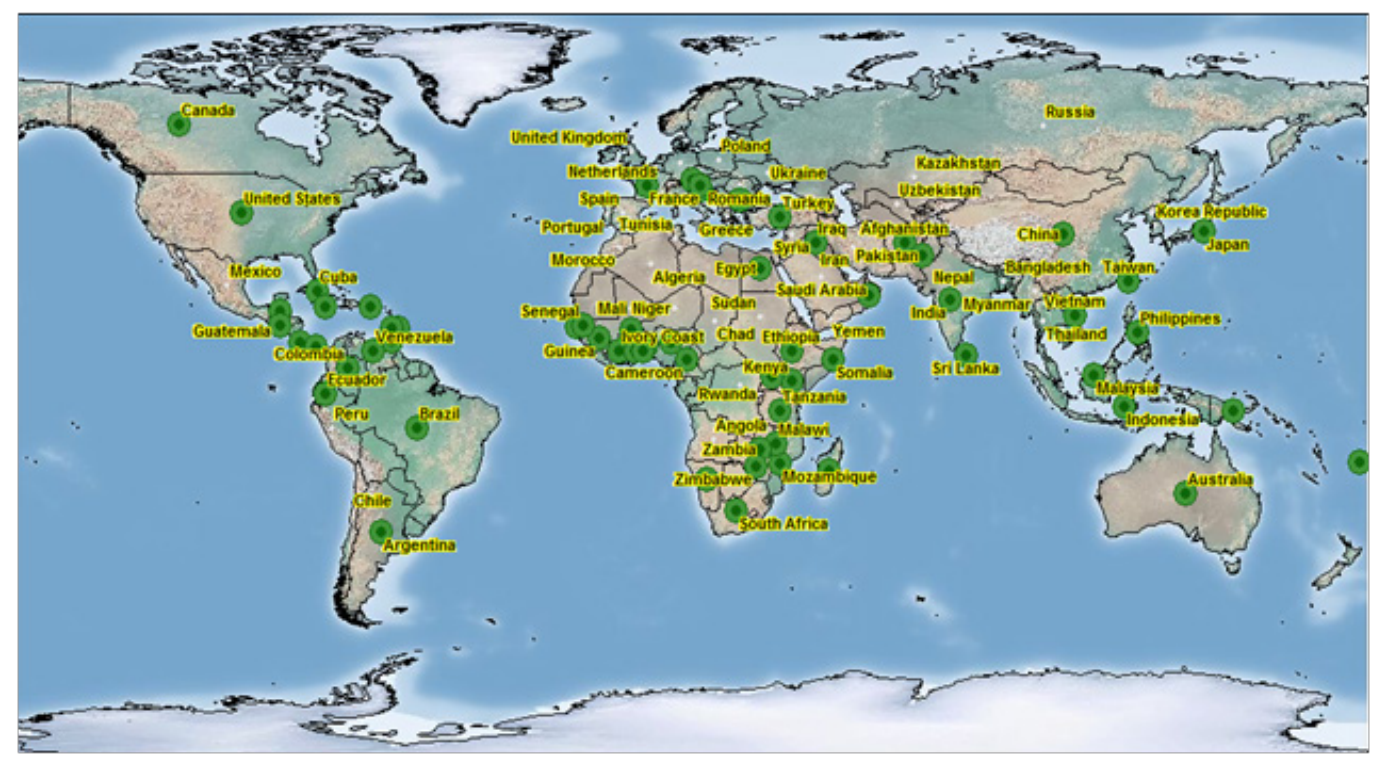

Figure IA World distribution of Pratylenchus zeae 


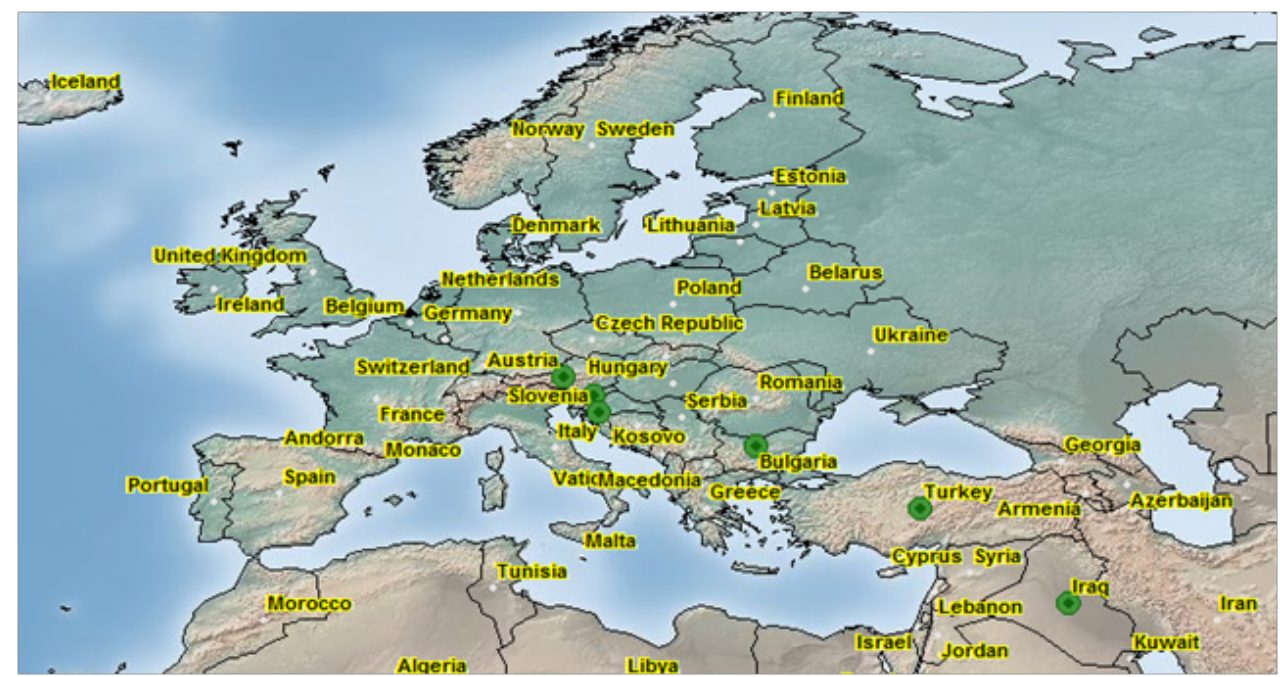

Figure IB Current detailed distribution of P. zeae in Europe.

Table I CLIMEX parameter values used to model ecoclimatic suitability for P. zeae

\begin{tabular}{lll}
\hline Parameter & Description & Valuea \\
\hline & Temperature & \\
DV0 & Lower temperature threshold for growth & $10^{\circ} \mathrm{C}$ \\
DV1 & Lower optimum temperature & $15^{\circ} \mathrm{C}$ \\
DV2 & Upper optimum temperature & $30^{\circ} \mathrm{C}$ \\
DV3 & Upper temperature threshold for growth & $35^{\circ} \mathrm{C}$ \\
& Moisture & \\
SM0 & Lower soil moisture threshold for growth & 0.1 \\
SM1 & Lower optimum soil moisture & 0.4 \\
SM2 & Upper optimum soil moisture & 0.7 \\
SM3 & Upper soil moisture threshold for growth & 1.5 \\
& Heat stress & \\
TTHS & Temperature Threshold for Heat Stress & $35^{\circ} \mathrm{C}$ \\
THHS & Heat stress accumulation rate & $0.002 \mathrm{week}-1$ \\
& Wet stress & \\
SMWS & Soil Moisture threshold for Wet Stress & 1.6 \\
HWS & Wet stress accumulation rate & $0.0015 \mathrm{week}-1$ \\
PDD & Number of degree-days above DV0 & $630 \mathrm{~b}, 945 \mathrm{c}, 1260 \mathrm{~d}$ degree- \\
& necessary to complete one generation & days \\
\hline
\end{tabular}

${ }^{a}$ Values without units are dimensionless indices.

bLow PDD value

cMean PDD value

¿Upper PDD value 
Heat stress parameter: The heat stress helps in restricting the distribution of the lesion nematode $P$. zeae to the warm parts of Europe. Because heat stress cannot logically accumulate within the temperature range suitable for growth, heat stress was set to accumulate as temperatures increase above DV3, the upper threshold for growth $\left(35^{\circ} \mathrm{C}\right)$. The rate accumulation parameter (THHS) was set to preclude the persistence of $P$. zeaein areas of Europe that are outside the known range of the lesion nematode.

Wet stress parameter: Wet stress in comparison to heat stress, cannot occur below the upper soil moisture threshold for growth (SM3). This parameter was therefore set to occur when the soil moisture exceeds the upper soil moisture threshold for growth (SM3) which is 1.5.

Degree-days per generation (PDD): The annual thermal accumulation (number of degree-days above DV0 $\left[10^{\circ} \mathrm{C}\right]$ ) necessary for $P$. zeae to complete a generation was adjusted to barely allow persistence at locations where $P$. zeae has been recorded in Europe. To determine the PDD values, CLIMEX fits a sine function to the minimum and maximum temperatures and then calculates the integral of the function above DV0.22 The PDD parameter is related to the length of the reproductive season, so it is ecologically important.

\section{Pest risk analysis}

The pest risk analysis (PRA) of Pratylenchus zeae on maize in Belgium and the Netherlands was conducted using the Pest Risk Assessment guideline of European and Mediterranean Plant Protection Organization (EPPO).$^{33}$ The EPPO pest risk assessment scheme (PM5/3(5) used for this study, provides detailed instruction based on EPPO experience, for the following three parts of the pest risk analysis: initiation, pest risk assessment and economic impact assessment and pest risk management. It provides a scheme for deciding whether a risk exists and for quantitative assessment of that risk, based on questions to which replies are given on a 1-9 scale. Guidelines on Pest Risk Analysis, i.e. a checklist of required information (PM 5/1-1) and a simple quick-PRA scheme (PM5/2-2) are also available. The latter one is only used when immediate action has to be taken on interception of a pest and therefore not used in this study. All the three stages involved in a PRA were used for this study. These include:

i. Initiation Stage (stage one): This stage seeks to identify the reasons for the PRA and the pest(s) of concern in the PRA area.

ii. Pest Risk Assessment Stage (stage two): This stage identifies and quantifies the risk of a particular pest to a particular PRA area, in terms of the probability of its introduction and its potential economic impact.

iii. Pest Risk Management Stage (Stage three): This Stage can only be conducted after a scientifically based risked assessment has been performed. The purpose of pest risk management is to decide:

iv. Whether the risk from the pest is such that phytosanitary measures are required to reduce the risk to an acceptable level.

v. Which measure (s) can or should be applied. ${ }^{34}$

A checklist of information required for pest risk analysis (PRA) was also used. This checklist contains all the information that should be considered before deciding that a particular organism qualifies to be declared as quarantine pest. The list is intended to be used in conjunction with a stepwise decision-making scheme on pest risk assessment; schemes of this type are being developed, at different levels of complexity, by EPPO and the Food and Agricultural Organization (FAO) (Table 1).

\section{Results and discussion}

\section{Climex}

Pratylenchus zeae was run with CLIMEX with different parameter values for PDD (Table 1), resulting in maps showing its potential distribution in Europe in general and in Belgium and The Netherlands in particular as well as the potential world distribution. The three calculated PDD values used were; 630, 945 and 1260, i.e. lower, mean and upper values respectively. The symbols on the maps represent the EI (Ecoclimatic Index), which integrates the Annual Growth Index with the Annual Stress. The EI can be seen as the climatological suitability of a location for a particular species. The value of EI lies between 0 and 100; the dots on the maps are in proportion to the EI values $(1-100 \%) ; 0 \%$ is represented as a cross.

In the CLIMEX run with relatively low PDD (minimum degreedays above limiting low temperature) of $630\left(21\right.$ days $\times 30^{\circ} \mathrm{C}$; Figure 2) $P$. zeae can be seen to have the potentials of being established in Belgium and the Netherlands, though it can be established too in other European countries out of Bulgaria, Austria, Slovenia, Croatia and Turkey from where it has been reported in Europe. The prediction shows an increase in northern distribution i.e. the potential distribution of Pratylenchus zeae is limited more to the northern European countries like England, Germany, Switzerland, Ireland and Scotland although such a high temperature would rarely be obtainable in these areas.

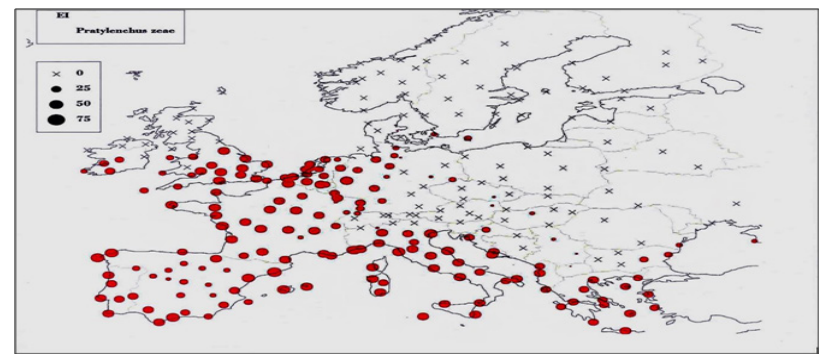

Figure 2 Predicted CLIMEX distribution of Pratylenchus zeae in Europe at PDD 630.

Pratylenchus zeae cannot thrive under extremely low temperatures and therefore cannot become established in the countries with extreme cold climatic conditions. Figure 1B shows that this pest is currently not present in the Scandinavian countries like Norway, Denmark, Finland and Sweden. A comparison of Figure 1B and Figure 2 at a low PDD value of 630 equally demonstrates that this pest cannot become established in the eastern European countries like Ukraine, Russia, Serbia, Belarus, and Lithuania among others. These regions are known also for extreme cold weather conditions and may thus justify why the pest has not be reported in any of the countries.

The distribution map of CLIMEX run with mean PDD value $945\left(27\right.$ days $\left.\times 35^{\circ} \mathrm{C}\right)$ Figure 3 ) shows that the pest cannot become established in the Netherlands, but can become established in Belgium as well as in France, Spain and the entire Mediterranean area. The mean PDD was chosen to make a more reliable prediction. As a check, the mean PDD correlates with countries where it has been introduced 
such as $\operatorname{Japan}^{35}$ and Bulgaria, ${ }^{17}$ hence making the mean value even more reliable. CLIMEX analysis with the mean PDD value of 945 shows that $P$. zeae can also not become established in countries like Germany, Czech Republic and Hungary. The pest has not been recorded in any of these countries as evident in Figure 1B. Therefore, under these conditions P. zeae can't establish in these regions upon introduction.

The CLIMEX run with a relatively high PDD value 1260 (84 days $\mathrm{x} 15^{\circ} \mathrm{C}$; Figure 4) makes $P$. zeae not being able to be established in both PRA areas-Belgium and the Netherlands. The potential distribution of the species becomes limited to the southern European countries: Spain, Greece, Italy, and southern France. This pest has previously not been reported in any of these countries as evident on Figure 1B However, the pest has been previously recorded in Turkey as can be seen in Figure 1B. This also suggests that countries with the same ecoclimatic conditions as Turkey are at potential risk of establishment of the pest upon introduction. It also shows that Pratylenchus zeae cannot establish in Belgium and the Netherlands. Figure 5 shows a world prediction of $P$. zeae at mean PDD 945. The figure shows a CLIMEX prediction hich indicates that most of the countries around the south of Africa, most parts of east and west Africa as well as some countries in the north of the continent e.g. Libya, Algeria, Tunisia and also Egypt ${ }^{36-38}$ where it is already present, are favorable areas of establishment when introduced. In Europe, most of the regions around the Mediterranean Sea e.g. Malta, Italy, Spain, Greece are of potential danger. Also, most of the areas in central and southern America e.g. Mexico, Costa Rica, Cuba are of potential danger while the cold parts of North America are risk free probably due to the cooler climate obtainable in these regions. Other countries of potential danger are Thailand, Chile and New Zealand.

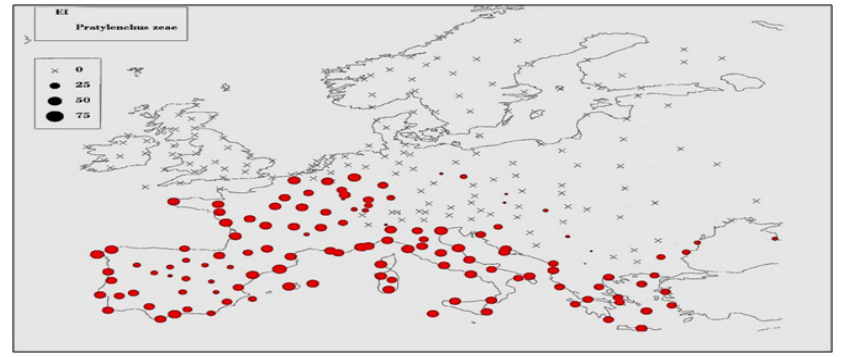

Figure 3 Predicted CLIMEX distribution of Pratylenchus zeae in Europe at PDD 945.

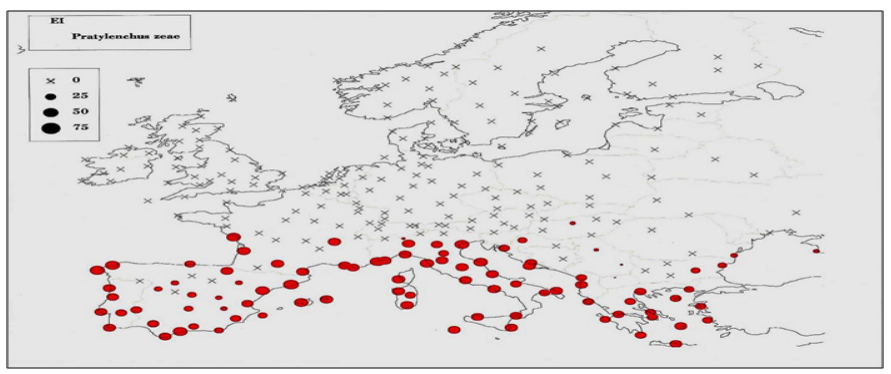

Figure 4 Predicted CLIMEX distribution of Pratylenchus zeae in Europe at PDD 1260

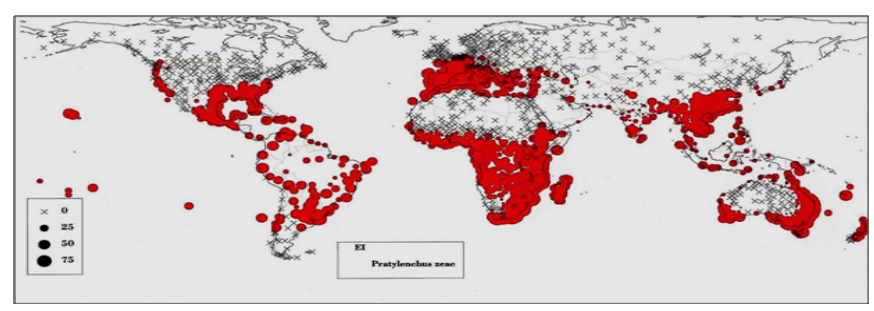

Figure 5 Predicted World distribution of Pratylenchus zeae at PDD 945.

\section{Pest risk assessment}

Pratylenchus zeae does not occur in the PRA areas-Belgium and the Netherlands and has never been subjected to a PRA nationally or internationally. For this study, the main host of concern was maize but Pratylenchus zeae, which does not require a vector nor an alternate host to complete its life cycle and also being a cosmopolitan species, has other hosts as wheat, barley and several grasses, ${ }^{39}$ found in the PRA area, although only maize and wheat are grown in most parts of Belgium and the Netherlands. The geographic distribution of the pest, which in its current area of distribution causes significant damage, includes ecoclimatic zones similar with those in Belgium. Therefore, the organism present a risk to Belgium and not the Netherlands as observed with CLIMEX.

Because of the large volume of consignments of plant and plant products being imported into the PRA area from other infested countries Pratylenchus zeae can enter the PRA area through ship and air transportation. Introduction of the pest can also occur through transportation of soil, soil and plant (host) and the hosts in containers and packaging, plants and plant products moving in trade, trains and road transport. The chances of entry are equally higher because of the wide host range of the pest. The pest, which can survive existing cultivation, is likely to be associated with the pathways at origin. Pratylenchus zeae, which is very likely to survive in transit, is also likely to survive or remain undetected during existing phytosanitary procedures. The reproductive strategy (parthenogenesis) of Pratylenchus zeae and duration of life cycle is very likely to aid establishment, also if relatively very low populations of the pest become established.

The climatic conditions in parts of the PRA areas that would affect pest establishment are quite similar to that in parts of the current areas of distribution. Pratylenchus zeae has been reported in Bulgaria, whose climatic conditions are comparable with southern Belgium. The pest cannot become established in the Netherlands as observed with CLIMEX, so Belgium is on the edge of its distribution and therefore the impact of this species is probably relatively low in this region. However, the species could be spread to southern Europe and there it is likely to have more effect.

The pest, which is not likely to be eradicated from the PRA areas once established, is also not very likely to be prevented by control measures already used against other pest during the growing of the crop. Control measures such as the use of resistant variety and biological control for example, used against other pests are normally likely to prevent establishment for some diseases. The pest is likely to be prevented by natural enemies already present in the PRA area such as soil fungi and Pasteuria penetrans. However, little is known about P. zeae. Crop rotation could be useful to control Pratylenchus 
$z_{e a e^{40,41}}$ organic soil amendments ${ }^{42}$ use of botanicals ${ }^{43}$ as well as weed-free fallow, ${ }^{44}$ oilcakes and nematicides. ${ }^{45,46}$ Chemical control is not economically justifiable and has been banned in the PRA area.

The pest is likely to survive or remain undetected if associated with crops that are not well known to be host e.g. nematodes resembling Pratylenchus zeae were detected in pods of groundnut in India. ${ }^{47}$ The nematode can also be miss-identified or confused easily with other Pratylenchidae, making it difficult to be detected during phytosanitary procedures. The pest with no race known, although not impossible as the pest has a wide host range, has been introduced into new areas (e.g. in Japan, Bulgaria and the USA), outside its original range (India).

Within its existing geographic range, Pratylenchus zeae causes important economic damage especially on maize, rice, sugarcane and tobacco, and much of the PRA area is likely to suffer damage from the pest, though the environmental and social damages it causes are of little importance. Considering the ecological conditions in the PRA areas, the direct effect of the pest on crop yield and/or quality is not likely to be high because of cool climatic conditions in the PRAarea. Pratylenchus zeae may likely not have a significant effect on consumer demand in these areas, as well as on the export market since maize is not exported.

The pest is not likely to develop resistance to plant protection products and may not posses much difficulty in control. The control measures, which are likely not to disrupt existing biological or integrated systems for control of other pests, may not have other undesirable side effects on human health or the environment since the use of chemicals have been banned in the PRA-area.

\section{Conclusion}

CLIMEX, as a simulation model, has its limitations. It only works with climatological data and climate-related species characteristics. Other physical and biological factors such as soil type, dispersion capability and predators are ignored. The program works with longterm climatological data, and it cannot discriminate between favorable and unfavorable years. With this in mind, and taking into consideration the analysis of the PRA guidelines, the following conclusion can be made on this study: Pratylenchus zeae can become established in Belgium but unlikely in the Netherlands although its effect on crop yield maybe low due to cool climatic conditions in this area. The pest however, does not have the characteristics of a quarantine organism due to its relatively low impact after introduction.

\section{Acknowledgements}

Wethank Ir. M. Bram de Hoop of the plant protection service in the Netherlands for introducing us into the world of Pest Risk Analysis, Dr. Dirk Boer, the CLIMEX specialist for introducing and demonstrating CLIMEX to us. Dr. Ir. N.M. Horn and Ir. H. Hendricks for providing us with valuable materials and useful comments for the project as well as Dr. Bert Kohlmann of Earth University, Costa Rica for his valuable suggestions for the manuscript. Financial assistance was provided by the Flemish Interuniversity council, Belgium.

\section{Conflict of interest}

The author declares no conflict of interest.

\section{References}

1. Graham TW. Nematode root rot of tobacco and other plants. South Carolina Agricultural Experiment Station Bulletin 390; 1951.

2. McDonald AH, Nicol JM. Nematode parasites of cereals. In: Luc et al. Editors. Plant Parasitic Nematodes in Subtropical and Tropical Agriculture. 2nd ed. Wallingford, UK: CABI Publishing. 1999. p. 131191

3. Barbosa BFF, Santos JM, Barbosa JC, et al. Aggressiveness of Pratylenchus brachyurus to sugarcane, compared with key nematode P. zeae. Nematropica. 2013;43(1).

4. Adiko A. Plant parasitic nematodes associated with plantain Musa paradisiaca (AAB) in the Ivory Coast. Revue Nérnato. 1988;11(1):109113.

5. Diaz-Silveira, Modesto Fernandez, Herrera, et al. An overview of Nematological Problems in Cuba. Nematropica. 1998;28(2):151-164.

6. Arim OJ, Waceke JW, Waudo SW, et al. Effects of Canavalia ensiformis and Mucuna pruriens intercrops on Pratylenchus zeae damage and yield of maize in subsistence agriculture. Plant Soil. 2006;284(1-2):243-251.

7. Coyne D, Plowright R. Assessment of the importance of individual plant parasitic nematode species in a community dominated by Heterodera sacchari on upland rice in Côte d'Ivoire. Nematology. 2002;4(6):661-669.

8. Fourie H, McDonald AH, Loots GC. Plant parasitic nematodes in field crops in South African Soybean. Nematology. 2001;3(5):447-454.

9. Khan A, Sayed M, Shaukat SS. Nematodes associated with papaya in Sindh (Pakistan). Sarhad J Agric. 2007;23(1):145-147.

10. Prot JC, Matias DM. Effects of Water Regime on the Distribution of Meloidogyne Graminicola and Other Root-Parasitic Nematodes in a Rice Field Toposequence and Pathogenicity of M. Graminicola on Rice Cultivar Upl R15. Nematologica. 1995;41(1):219-222

11. Olowe T, Corbett DCM. Aspects of the biology of Pratylenchus Brachyurus and P. zeae. Nematologica. 1976;22(2):202-211.

12. Magbool MA, Hashmi S. Population trends of parasitic nematodes in different cropping sequences and the effect on yield of corn cv. AZAM. International Nematology network Newsletter. 1986;3:34-38.

13. Obuezie CB, Ikpeze O. Parasitic nematodes of maize farms at ObaidemiliSouth Local Government Area of Anambra State Nigeria. Journal of Occupational Safety and Environmental Health (JOSEH). 2012;1(1):7378

14. Walters MC. The Possible status of parasitic nematodes as limiting factors in maize production in South Africa. Proceedings second South Africa maize breeding symposium, Pietermartzburg, technical service Republic of South Africa. 1979;142:112-118.

15. Rich JR, Johnson JT, Hodge CH. Corn Response to Subsoiling and Nematicide Application. J Nematol. 1985;17(4):404- 407.

16. Frank K, John D, Pangirayi T, et al. Grain Yield and Heterosis of Maize Hybrids under Nematode Infested and Nematicide Treated Conditions. $J$ Nematol. 2011;43(3-4):209-219.

17. Stoyanov D. Parasitic species of nematodes on maize. Rastitelna Zashchita. 1977;25(10):23-24.

18. Fauna Europaea; 2013.

19. Crop Protection Compendium, Wallingford, UK, CAB International, CDROM, VERSION; 2001. 
20. Bulletin OEPP/EPPO. PM 5/3(1), Guidelines on Pest Risk Analysis (PRA). No 3. Pest Risk Assessment scheme, Bulletin OEPP/EPPO, bulletin. 1997;27:281-305.

21. Sutherst RW, Maywald GF. A computerized system for matching climates in ecology. Agriculture, Ecosystems \& Environment. 1985;13(3-4):281299.

22. Sutherst RW, Maywald GF, Yonow T, et al. Predicting the Effects of Climate on Plants and Animals. CD-ROM and User Guide. Melbourne, Australia: CSIRO Publishing; 1999.

23. Brasier CM. Phytophthoracinnamomiand oak decline in southern Europe. Environmental constraints including climate change. Ann For Sci. 1996;53(2-3):347-358.

24. Kriticos DJ, Suthers RW, Brown JR, et al. Climate change and the potential distribution of Acacia niloticassp. niloticain Australia. Journal of Applied Ecology. 2003;40(1):111-124.

25. Matsuki M, Kay M, Serin J, et al. Potential risk of accidental introduction of Asian gypsy moth (Lymantria dispar) to Australasia:Effects of climatic conditions and suitability of native plants. Agricultural and Forest Entomology. 2001;3(4):305-320.

26. Vera MT, Rodriguez R, Segura DF, et al. Potential geographical distribution of the Mediterranean fruit fly, Ceratituscapitata(Diptera:Tephritidae), with emphasis on Argentina and Australia. Environmental Entomology. 2002;31(6):1009-1022

27. Beddow JM, Kriticos D, Pardey PG, et al. Potential Global Crop Pest Distributions Using CLIMEX: Harvest Choice Applications. Harvest Choice; 2010.

28. Smith L. Prediction of the geographic distribution of the psyllid, Arytinnis hakani (Homoptera: Psyllidae), a prospective biological control agent of Genista monspessulana, based on the effect of temperature on development, fecundity, and survival. Environ Entomol. 2014;43(5):1389-1398.

29. Latham DR, Mills NJ. Effects of temperature on the life history parameters and population growth rates of Hyalopterus pruni (Hemiptera:Aphididae). J Econ Entomol. 2011;104(6):1864-1869.

30. He SY, Ge XZ, Wang T, et al. Areas of potential suitability and survival of Dendroctonus valens in china under extreme climate warming scenario. Bull Entomol Res. 2015;105(4):477-484.

31. Kriticos DJ, Randall RP. A comparison of systems to analyze potential weed distributions. In: RH Groves et al. Editors. Weed Risk Assessment. Melbourne, Australia: CSIRO Publishing; 2014. p. 61-79.

32. Acosta N, Malek RB. Influence of temperature on population development of eight species of Pratylenchus on soybean. J Nematol. 1979;11(3):229 232 .
33. Bulletin OEPP/EPPO. PM 5/3(5) Decision-support scheme for quarantine pests; 2011.

34. CABI; EPPO. Distribution Maps of Plant Diseases 2001 No. 1st ed. 2001. $830 \mathrm{p}$.

35. Gotoh A. Geographic distribution of Pratylenchus spp. (Nematoda: Tylenchida) in Japan. Bulletin of the Kyushu Agricultural Experiment Station. 1974; 17:139-224

36. Di Vito M, Greco N, Halila HM, et al. Nematodes of cool-season food legumes in North Africa. Nematologia Mediterranea. 1994;22:3-10

37. Ismail AE, El-Nagdi WMA, Hasabo SA. Efficacy of some Local Isolates of Saccharomyces cerevisiae, Trichoderma harzianum and T. ressei as Bioagents for Controlling Helicotylenchus exallus and Pratylenchus zeae Infecting Jasmine in Egypt. Egypt J Phytopathol. 2005;33(2):27-40.

38. Korayem AM, Mohammed MMM. High yielding hybrid maize cultivar tolerant to Pratylenchus zeae in Egypt. Pakistan Journal of Nematology. 2010;28(1):109-114.

39. Stirling GR, Halpin NV, Dougall A, et al. Status of winter cereals, other rotation crops and common weeds as hosts of lesion nematode (Pratylenchus zeae). Proc. Aust. Soc. Sugar cane technol. 2010;32:62-70.

40. Aung T, Pro JC. Effects of crop rotations on Pratylenchus zeae and on yield of rice cultivar UPL Ri-5. Revue de Nématologie. 1990;3(4):445447.

41. Santana SM, Dias-Arieira CR, Biela F, et al. Manejo de Pratylenchus zeae por plantas antagonistas, em solos de áreas de cultivo de caña-de-azúcar. Nematropica. 2012;42:63-71.

42. Oka Y. Mechanisms of nematode suppression by organic soil amendments A review. Applied Soil Ecology. 2010;44(2):101-115.

43. Archana US, Prasad D. Management of Plant-parasitic Nematodes by the Use of Botanicals. Journal of Plant Physiology \& Pathology. 2014;2:1.

44. Hillocks RJ. The potential benefits of weeds with reference to small holder agriculture in Africa. Integrated Pest Management Reviews. 1998;3:155-167.

45. Plowright RA, Matias D, Aung T, et al. The effect of Pratylenchus zeae on the growth and yield of upland rice. Revue de Nématologie. $1990 ; 13(3): 283-292$.

46. Sahoo CR, Sahu SC. Studies on the effect of different oil-cakes and two nematicides in the control of lesion nematode, Pratylenchus zeae in rice. Annals of Plant Protection Sciences. 1994;2:30-32.

47. Singh GP. Nematode pod rot and rust- two serious diseases of groundnut in Ranchi. Indian Phytopathology. 1978;31(3):357-358. 